\title{
Napo (Hemiptera, Cicadellidae): primeiro registro no Brasil e descrição de uma nova espécie ${ }^{1}$
}

\author{
Keti M. R. Zanol ${ }^{2}$
}

1. Contribuição n 1589 do Departamento de Zoologia, Universidade Federal do Paraná.

2. Departamento de Zoologia, Universidade Federal do Paraná, Caixa Postal 19020, 81531-990 Curitiba, Paraná, Brasil. (zanol@ufpr.br)

\begin{abstract}
Napo (Hemiptera, Cicadellidae): first record for Brazil and description of a new species. Napo Linnavuori \& DeLong, 1976 is reported for the first time in Brazil. A new species, Napo bellus sp. nov., is described and illustrated.
\end{abstract}

KEYWORDS. Brazil, Deltocephalinae, Napo, new species, new records.

RESUMO. Napo Linnavuori \& DeLong, 1976 é registrado pela primeira vez no Brasil. Uma nova espécie, Napo bellus sp. nov. é descrita e ilustrada.

PALAVRAS-CHAVE. Brasil, Deltocephalinae, espécie nova, Napo, nova ocorrência.

LinNAVUORI \& DeLong (1976) descreveram Napo, monotípico, tendo como espécie-tipo $N$. brazosellus (Peru). No presente trabalho, descreve-se $N$. bellus $\mathrm{sp}$. nov., sendo o primeiro registro de espécie do gênero no Brasil.

$\mathrm{O}$ material estudado pertence à Coleção de Entomologia Padre Jesus Santiago Moure, Departamento de Zoologia, Universidade Federal do Paraná (DZUP).

\section{Napo bellus sp. nov.}

(Figs. 1-6)

Holótipo macho. Coroa com duas manchas arredondadas na margem anterior e uma mancha triangular, junto à sutura coronal, marrom-escuras; região discal com duas grandes manchas alaranjadas margeadas de amarelo. Face amarela. Pronoto marromclaro com duas manchas, de contorno irregular, alaranjadas. Escutelo alaranjado; triângulos basais e uma mancha triangular mediana, marrom-escura. Asas anteriores hialinas, com reflexo marrom-claro; margem costal e margem anal marrom-escuras.

Cabeça (Fig. 1) de comprimento uniforme; superfície microesculturada; sutura coronal alcançando a metade do comprimento da coroa; ocelos levemente abaixo da margem anterior, invisíveis dorsalmente; distância ocelo-ocular maior que o diâmetro do ocelo. Anteclípeo mais largo no ápice. Sutura frontoclipeal alcançando os ocelos. Genas sinuosas.

Pronoto (Fig. 1) mais estreito que a cabeça; superfície lisa. Asas anteriores (Fig. 2) com duas células anteapicais; apêndice não alcança $\mathrm{M}_{3+4}$. Espinulação das tíbias anteriores $1+4$ e dos fêmures posteriores $2+2+1$.

Pigóforo (Fig. 4) arredondado no ápice com poucas macrocerdas apicais e sem apêndices; margens ventrais esclerotinizadas, irregularmente denticuladas. Valva genital (Fig. 3) semicircular. Placas subgenitais (Fig. 3) longas e estreitas; macrocerdas dispostas longe da margem. Estilos (Fig. 3) com apófises voltadas para fora, como um bico. Edeago (Figs. 5, 6) simétrico, curvo para cima, sem apêndices; gonóporo subapical, na superfície ventral. Conetivo de braços paralelos, mais longo que o próprio edeago.

Comprimento total: $5,9 \mathrm{~mm}$.

Material-tipo. Holótipo ơ, BRASIL, Mato Grosso: Nobres (Rio Serragem), 30.V.1983, S. Silva leg. Parátipos, BRASIL, Mato Grosso: B. Bugres, E. E. S. Araras, O', 17.II.1987, Y. Willis leg.; Paraná: Perobal, O', VIII.1996, A. Kumagai leg.

Comentários. Napo bellus sp. nov. é semelhante a $N$. brazosellus Linnavuori \& DeLong, 1976, diferindo desta pelo edeago; em $N$. bellus, o edeago é simples, enquanto que em $N$. brazosellus apresenta um par de apêndices basais.

\section{REFERÊNCIAS BIBLIOGRÁFICAS}

Linnavuori, R. \& DeLong, D. M. 1976. New Neotropical leafhoppers from Peru and Bolivia (Homoptera: Cicadellidae). Revista Peruana de Entomologia 19(1):29-38. 


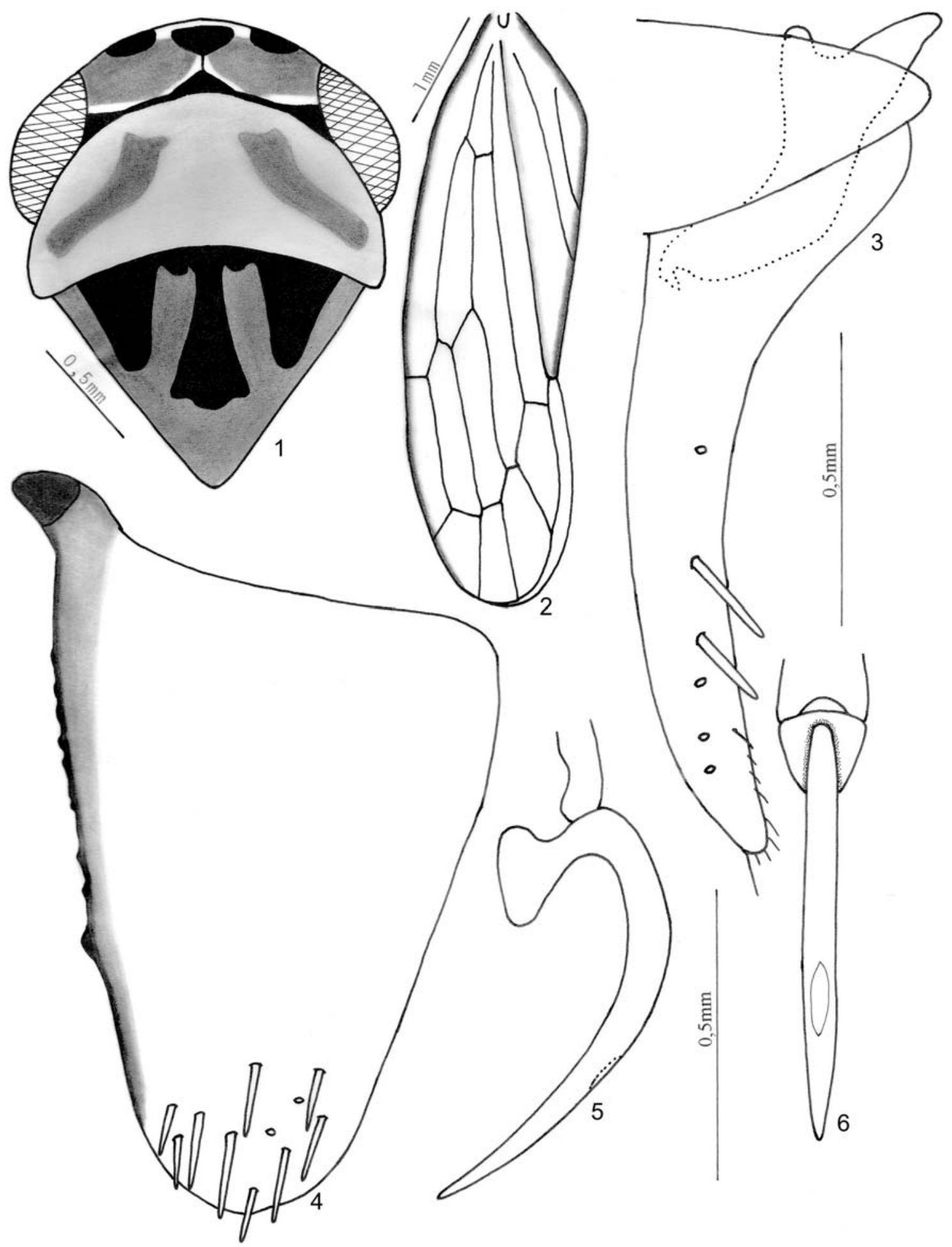

Figs. 1-6. Napo bellus sp. nov.: 1, cabeça, pronoto e escutelo; 2, asa anterior; 3, valva genital, placa subgenital e estilo; 4, pigóforo, lateral; 5, 6, edeago: 5, lateral; 6 , ventral.

Recebido em agosto de 2005. Aceito em novembro de 2005. ISSN 0073-4721

Artigo disponível em: www.scielo.br/isz 